\title{
Pedro Henríquez Ureña en México
}

W L paso de Pedro Henríquez Ureña por México dejó huella

C indeleble. Los pensadores mexicanos que mayor influencia han tenido sobre el desarrollo de las letras modernas en ese país bebieron copiosamente del manantial de su amplia cultura y asombrosa erudición. Las obras de estos escritores -Antonio Caso, José Vasconcelos, Alfonso Reyes- trascienden la influencia del maestro dominicano. ¿Con qué secreto contaba este joven de veintidós años -llegó a México en 1906- para poder ejercer su influencia, en un ambiente extranjero, sobre mentalidades de la talla de Caso, Reyes y Vasconcelos? El haber sido aceptado tal vez se deba a que los jóvenes a los cuales se unió - a su llegada a tierras de Anáhuac-vieron en él lo que precisamente les faltaba a ellos: una mentalidad bien disciplinada; una rica erudición; un estilo formado y, lo más importante, un gran espíritu emprendedor. Sin su esfuerzo, el grupo de jóvenes entusiastas que se reunía en los salones de la Preparatoria para dictar y oír conferencias nunca se hubiera organizado en "Ateneo de la Juventud". Antonio Caso, debido a su "carácter apático y a veces insociable —nos dice José Vasconcelos- no hubiera mantenido alianzas sin la colaboración de Henríquez Ureña".

Mas, antes de discutir la actuación de don Pedro dentro del "Ateneo de la Juventud", esa organización que tanta influencia había de tener en el desarrollo de las letras mexicanas, echemos un vistazo a los acontecimientos ocurridos entre 1906 y 1909, años de gran trascendencia en el cambio ideológico que

1 Ulises Criollo, $5^{\text {a }}$ ed. (México, Botas, 1936), p. 311. 
se verificó en México y que culminó en 1910 con la Revolución Mexicana.

Tan pronto como don Pedro llega a la ciudad de México se incorpora al grupo que Alfonso Cravioto había reunido en torno a la revista Savia Moderna, establecida en mayo de 1906 con el objeto de atraer a todos aquellos intelectuales que representaban las principales tendencias filosóficas y literarias de la época. Allí conoció Henríquez Ureña a los jóvenes literatos mexicanos que más prometían. "Desde 1906 -dice Alfonso Reyes- me había vineulado al grupo de Savia Moderna, en cuya redacción conocí, entre otros, a Pedro Henríquez Ureña, que representa toda una etapa de mi formación juvenil". ${ }^{2}$ Los otros miembros del grupo de Savia Moderna, además de Cravioto y Reyes, eran Luis Castillo Ledón - que había colaborado con Cravioto en fundar la revista-, los filósofos Antonio Caso y José Vasconcelos, el arquitecto Jesús T. Acevedo, el pintor Diego Rivera y los literatos Rafael López, Manuel de la Parra, Eduardo Colín y Ricardo Gómez Robelo. Caso, debido a su elocuencia, a su eficacia mental, a su naturaleza irresistible, se convirtió en el director de este grupo de jóvenes. Pero la influencia de Don Pedro era, nos dice Reyes, más honda, más total. "Sin saberlo, enseñaba a ver, a oír, a pensar, y suscitaba una verdadera reforma en la cultura pesando en su pequeño mundo con mil compromisos de laboriosidad y conciencia. Era, de todos, el único escritor formado, aunque no el de más años. No hay entre nosotros, ejemplo de comunidad y entusiasmo espirituales como los que él provocó. El peruano Francisco García Calderón escribió de él : 'alma evangélica... inquietada por los grandes problemas, profundo erudito en letras castellanas, sajonas, italianas..." Díaz Mirón, que lo admiraba, lo llamaba 'dorio'. $\mathrm{Y}$ todos nos apellidamos de su amistad"."

Por aquellos años (1907), don Pedro traduce a Walter Pater," interés que es manifiesto en su ensayo "El espíritu

2 La experiencia literaria (Buenos Aires, 1942), p. 127.

3 Alfonso Reyes, Rubén Dario en México. Memorias literarias. Publicado en la revista Nuestro Tiempo, junio, 1916 (Madrid, Imprenta de "Alrededor del Mundo", 1916), p. 8.

4 Walter Pater, Estudios griegos (México, edición de la Revista Moderna, 
platónico" (1907), recogido en su libro Horas de estudio (París, 1910). En compañía de Alfonso Reyes y José Vasconcelos, leía a los griegos. El resultado de dichas lecturas es su tragedia El nacimiento de Dionisos (Nueva York, 1916), obra relacionada, por la inspiración, a la Ifigenia cruel de Reyes y al Prometeo vencedor de Vasconcelos. En su libro La experiencia literaria, Reyes hace memoria de esos estudios: "Y el mismo año de 1908 ... el afán por desentrañar la continuidad pagana que corre del mito antiguo al cristianismo nos llevó a celebrar una íntima fiesta literaria la noche de Navidad, fecha coincidente con la que se ha atribuido al nacimiento de Dionisos. Sobre este asunto escribió Pedro Henríquez Ureña una tragedia en prosa, según la manera del teatro ateniense, y yo cierto Coro de sátiros en el bosque... Ambas piezas fueron leídas en aquella velada" (La experiencia literaria, p. 128). Los escritores griegos fueron la pasión de este grupo de jóvenes; su lectura les atraía de tal manera, que se olvidaban del mundo exterior: "Una vez — dice don Pedro- nos citamos para releer en común el Banquete de Platón. Eramos cinco o seis esa noche; nos turnamos en la lectura, cambiándose el lector para el discurso de cada convidado diferente... La lectura acaso duró tres horas; nunca hubo mayor olvido del mundo de la calle, por más que esto ocurría en un taller de arquitecto, inmediato a la más populosa avenida de la ciudad". ${ }^{6}$ Alfonso Reyes recuerda esa reunión: "Era — nos dice_ la calle de Plateros. Era el taller de Jesús Acevedo. Eramos amigos unidos para siempre. Amanecía cuando cerramos el libro. Sólo entonces nos dimos cuenta de que había llovido toda la noche". ${ }^{7}$ Otro fruto de estas lecturas fue la obra Cuestiones estéticas (París,

1908). (Traducción de P. H. U.). Los primeros estudios que Hentíquez Ureña publicó en México aparecieron - en el año de 1907- en la Revista Moderna, la Revista Crílica y México Moderno. Uno de sus primeros trabajos de tema mexicano fue el que escribió sobre el poeta Jesús E. Valenzuela en México Moderno (1907). Para la bibliografía de P. H. U. ver Revista de filología bispánica, VIII (1946), págs. 194-210, y en este número la Crono-bibliografía... de E. Speratti Piñero.

5 Ver Alfonso Reyes, Pasado inmediato (México, 1941), pp. 47-48.

6 Pedro Henriquez Ureña, La cultura de las bumanidades, discurso de inauguración de las clases en la Escuela de Altos Estudios de México, 1914. Citado por Alfonso Reyes en Simpatías y diferencias (México, 1945), II, 294-95.

7 Simpatias $y$ diferencias, ed. cit., II, 295. 
1911) de Alfonso Reyes, publicada a instancias de don Pedro, a quien el autor dedica el primer ensayo del libro, "Las tres 'Electras' del teatro ateniense", fechado en 1908.

Además de los griegos, Henríquez Ureña leía, en compañía de don Antonio Caso, a Kant y a otros filósofos idealistas. Con frecuencia, las reuniones eran en casa del maestro Caso. Hablando de la Crítica de la razón pura de Kant, Caso evoca, nostálgicamente, la siguiente escena: "Nos trae el libro a la memoria días ya lejanos en que, en nuestra casa y compañía, don Pedro Henríquez Ureña, don José Vasconcelos, don Alfonso Reyes y don Martín Luis Guzmán ... leíamos y comentábamos a Kant en el texto de Perojo. Estas lecturas fueron para nosotros de incalculable significación y trascendencia. Pedro Henriquez Ureña poseía la versión inglesa de Max Müller, y solía agregar importantes notas eruditas a nuestras lecturas comentadas de los capítulos de la Estética y Analítica trascendentales". 8

Las lecturas de los filósofos tenían, también, un fin ulterior: buscar bases firmes sobre las cuales se pudiera combatir el positivismo de Comte. "Bajo el gobierno de Díaz - dice don Pedro - la vida intelectual de México había vuelto a adquirir la rigidez medioeval... el positivismo había reemplazado al escolasticismo en las escuelas oficiales, y la verdad no existía fuera de él. En teoría política y económica, el liberalismo del siglo XVIII se consideraba definitivo... Pero en el grupo a que yo pertenecía, el grupo que me afilié a poco de llegar de mi país a México pensábamos de otro modo. Eramos muy jóvenes (había quien no alcanzaba todavía los veinte años) cuando comenzamos a sentir la necesidad del cambio... Sentíamos la opresión intelectual, junto con la opresión política y económica de que ya se daba cuenta gran parte del país. Veíamos que la filosofía oficial era demasiado sistemática, demasiado definitiva, para no equivocarse. Entonces nos lanzamos a leer a todos los filósofos a quienes el positivismo condenaba como inútiles, desde Platón, que fue nuestro mayor maestro, hasta Kant y Schopenhauer. Tomamos en serio ( $\mathrm{O} O \mathrm{~h}$

s Antonio Caso, México: Apuntamientos de cultura patria (México, 1943), pp. 92 y 94 . 
blasfemia!) a Nietzsche. Descubrimos a Bergson, a Boutroux, a James, a Croce". ${ }^{9}$

La primera manifestación pública contra el positivismo oficial fue la que organizó este grupo de jóvenes en 1907, con el pretexto de oponerse a que don Manuel Caballero - a quien no le reconocían personalidad para recoger la tradición- reviviera la Revista Azul de Nájera. En mitin celebrado en la Alameda, Gómez Robelo criticó el positivismo prevalente en la vida pública. Por la noche, el grupo asistió a uña velada en el Teatro Arbeu, en donde el orador Jesús Urueta continuó el ataque. Tanto Don Pedro como su hermano Max - que vivió en México de 1907 a 1908 - firmaron el manifiesto de protesta, protesta que había de dar sus frutos. El 20 de marzo del año siguiente, en famoso discurso, don Justo Sierra condenó el positivismo oficial. De esa fecha parte una nueva época en la ideología nacional. No poco de ello se debe a los esfuerzos de don Pedro, el más activo miembro del grupo cuyas ideas prevalecieron a partir de esa fecha.

El resultado de este descontento fue la organización, en 1908, de la importante "Sociedad de Conferencias", en el Casino de Santa María la Ribera, y de la cual había de surgir el Ateneo de la Juventud. En la formación de ambas sociedades tuvo gran influencia - y así lo reconocen tanto Reyes como Henríquez Ureña- el arquitecto Jesús T. Acevedo; pero sin el espíritu formalista y académico de don Pedro el Ateneo no se hubiera organizado. "Mucho se ha hablado - dice Vasconcelos- en México del grupo del Ateneo y lo único cierto es que sin Pedro no habría existido. Su exigencia de sociabilidad nos llevó a trabajar en común, no obstante ser cada uno de nosotros radicalmente distinto, e inepto para trabajo común". ${ }^{10}$ El 28 de octubre de 1909, por lo tanto, la agrupación fundó el "Ateneo de la Juventud", presidido el primer año por el maestro Caso y el segundo por Alfonso Cravioto. ${ }^{11}$ ¿Y por

9 "La revolución y la cultura en México", en la Revista de filosofía, Buenos Aires, XXI (1925), 125-132; en particular, p. 127.

10 José Vasconcelos, "Vivió en los amigos", en Letras de México, núm. 125 (15 de agosto de 1946). Número dedicado a P. H. U.

111 Sobre la fundación del Ateneo de la Juventud, ver el artículo de Quijano, "El verdadero Ateneo", en Letras de México, núm. 19 (16 de sept., 1937), p. 2. 
qué -nos preguntamos- se escogió dicho nombre? Tal vez se deba a que ya en 1901 existía en Santo Domingo un "Ateneo de la Juventud" al cual pertenecían Pedro y Max, fundador este último de su órgano El Ideal.12

Uno de los primeros actos del Ateneo de la Juventud fue la organización de un ciclo de conferencias. La primera la sustentó el maestro Caso, quien habló sobre la filosofía moral de Hostos; la segunda Alfonso Reyes, sobre los Poemas Rústicos de Othón, y la tercera, el lunes 22 de agosto de 1910, en el salón de actos de la Escuela de Jurisprudencia, Pedro Henríquez Ureña. El tema que desarrolló esa noche fue: "La obra de José Enrique Rodó". Dichas conferencias, con otras por González Peña, José Escofet y José Vasconcelos, fueron recogidas en volumen $\mathrm{y}$ publicadas en México ese mismo año. ${ }^{13}$ Como podemos observar por los títulos de las conferencias, Caso y Vasconcelos -éste disertó sobre las ideas de Gabino Barredaeran los representantes, en el Ateneo, de la filosofía. En cambio, don Pedro y Alfonso Reyes representaban la literatura y la crítica literaria. Según ha recordado Vasconcelos, los críticos imprimieron al grupo "una dirección cultista, mal comprendida al principio, pero útil en un medio acostumbrado a otorgar palmas de genio al azar de la improvisación y fama perdurable, sin más prueba que alguna poesía bonita, un buen artículo, una ingeniosa ocurrencia..."14

De mayor importancia, por supuesto, es la campaña cultural con la que el Ateneo renovó el ambiente intelectual. "Bien pronto - dice Henríquez Ureña - nos dirigimos al público en conferencias, artículos, libros (pocos) y exposiciones de arte. Nuestra juvenil revolución triunfó, superando todas nuestras esperanzas ..." 15 El joven maestro dominicano era el verdadero animador del Ateneo. "En él -dice don Martín Luis Guzmán - figuró como voz orientadora infatigable - nunca se lo agradecerán bastante la cultura y las letras mexicanas-

12 Ver "Max Henríquez Ureña", en Esperanza Velázquez Bringas y Rafael Heliodoro Valle, Indice de escritores (México, 1928), pp. 128-131).

13 Conferencias del Ateneo de la Juventud (México, Imprenta Lacaud, 1910).

El estudio de P. H. U. sobre Rodó ocupa las págs. 63-83.

14 Ulises Criollo, ed. cit., p. 267.

15 "La revolución y la cultura en México", p. 127. 
Pedro Henríquez Ureña, alto espíritu dotado a la vez, por raro privilegio, de un talento adulto reposado y sabio y del más bello entusiasmo juvenil". ${ }^{16}$ Los ateneístas -podríamos agregar- establecieron los fundamentos y las direcciones esenciales del pensamiento y sensibilidades del presente; su estudio nos revela las corrientes intelectuales y literarias posteriores. Si don Pedro no hubiera vuelto de Santo Domingo en 1911 -año en que hizo una visita a su patria - la deuda que México tendría con él sería considerable. $Y$ en cambio, su actuación dentro del Ateneo fue solamente un aspecto de sus portentosas actividades literarias y culturales de aquellos años de intensa vida intelectual. "Estaba dotado - dice don Alfonso Reyes - de una laboriosidad que le era naturaleza, y ella poseía dos fuerzas: la ostensible que le era naturaleza, y la oculta. Leía y escribía junto a la sopa, en mitad de la conversación, delante de las visitas, jugando al 'bridge', entre los deberes escolares... A veces, llegué a preguntarme si seguía trabajando durante el sueño... Su pensamiento no descansaba nunca". 17

Entre las innumerables actividades que don Pedro llevó a cabo durante aquellos años, se encuentra la de compilar la importantísima Antología del Centenario, ${ }^{18}$ obra que marca una época en la historia de los estudios literarios en México. En la "Advertencia", calificada por Alfonso Reyes de "sobria y meditada",19 el maestro dominicano hace, por primera vez

16 A orillas del Hudson (México, 1920), p. 49.

17 "Evocación de Pedro Henríquez Ureña". Homenaje a su memoria of recido por la Secretaría de Educación Pública en el Palacio de Bellas Artes de México el 31 de mayo de 1946. Recogido en Grata compañia (México, 1948), pp. 205-215; también apareció como "Prólogo" a las Páginas escogidas de Pedro Henríquez Ureña (México, Secretaría de Educación Pública, 1946). La selección es de José Luis Martínez. Vol. 109 de la "Biblioteca Enciclopédica Popular". P. H. U. murió de un sincope cardíaco en el tren que le llevaba a La Plata la mañana del sábado 11 de mayo de 1946. Ver: Francisco Romero, "Cómo murió Pedro Henríquez Ureña", en el Repertorio Americano, XIVII (1951), p. 177.

18 Obra compilada bajo la dirección del señor Lic. D. Justo Sierra... por los señores don Luis G. Urbina, Don Pedro Henríquez Ureña y don Nicolás Rangel. Primera parte (1800-1821). 2 vols. (México, Imp. de Manuel León Sánchez, 1910).

19 "La Antologia del Centenario", reseña recrgilla en Obras completas de Al- 
en México, una penetrante crítica de las historias de la literatura mexicana hasta 1910, sobresaliendo sus apuntes acerca de Beristáin y Menéndez Pelayo. También le pertenecen varias de las biografías y, en el Apéndice al segundo tomo, el "Indice biográfico de la época", cuya introducción es una brillante reseña de la cultura mexicana de la época colonial, $y$ en la cual hace resaltar por primera vez la importancia del siglo XVIII. Para él, "el siglo XVIII fue, dentro de los límites impuestos por el régimen político de la colonia, acaso el siglo de mayor esplendor autóctono que ha tenido México". ${ }^{20}$ A pesar de ello, hasta hace pocos años la importancia del siglo XVIII era casi ignorada. Sólo en nuestros días se ha comenzado a estudiar sistemáticamente tan importante período de la cultura colonial mexicana.

Antes de ir a México, el joven dominicano ya había publicado un libro, cuyo título, Ensayos criticos (La Habana, 1905) apunta ya qué actividades han de ocuparle el resto de su vida. $^{21}$ El indicio se confirma con su segundo libro, Horas de estudio (París, 1910) - "ipara usted todas son horas de estudio!", le decía el maestro Caso- partes del cual fueron escritas en México; allí encontramos su primera apreciación de dos ateneístas: Antonio Caso y Alfonso Reyes. ${ }^{22} \mathrm{Al}$ mismo año pertenece también su mejor estudio histórico, "Hernán Pérez de Oliva", escrito en 1910 y publicado en la revista $C u b a$ Contemporánea, de La Habana, en 1914. Fue reimpreso en su libro Mi España (México, 1922) y también en Plenitud de España (Buenos Aires, 1940), con algunas adiciones en las notas; ensayo que sirve, dice Vitier, de ejemplo para su procedimiento en cosas de historia literaria.

El ańo de 1911, en México, marca el rompimiento con el

fonso Reyes (México, Fondo de Cultura Económica, 1955), I, 277-283. (Suscrita en México, agosto de 1910).

20 Antologia del Centenario (México, 1910), II, 661.

21 Nos es imposible citar aqui, debido a la naturaleza de este trabajo, todas las obras que don Pedro escribió en México o en torno a asuntos mexicanos; los lectores interesados pueden consultar la excelente Crono-bibliografia de Pedro Henríquez Ureña, de Emma Speratti 'Piñero, en este mismo número.

22 "Días alcióneos: Antonio Caso y Alfonso Reyes", en Horas de estudio (París, P. Ollendorff, 1910). Este trabajo apareció primero en la revista $L_{a}$ Cuna de América, de Santo Domingo, en 1908. 
pasadu. El 25 de mayo el Presidente Díaz por fin renuncia la presidencia, y Madero, cuatro meses más tarde, hace su entrada triunfal en la ciudad de México. Mas su gobierno es breve; su asesinato el 23 de febrero de 1913 desata una lucha civil que ha de retumbar en los más apartados rincones de la república. La vida cultural, y sobre todo la literaria, casi se paraliza. A fines de 1912 habían terminado las actividades del Ateneo, y por inicitiva de sus miembros se estableció la Universidad Popular. ${ }^{23}$ Al año siguiente, don Pedro ayuda a reorganizar la Escuela de Altos Estudios: "En 1913 -nos diceel doctor Chávez, hombre del antiguo régimen, que había vivido en esfuerzo continuo de adaptación a tendencias nuevas, se echó a buscar el concurso de hombres avanzados, dispuestos a trabajar grautitamente en la organización de la Escuela de Altos Estudios; la mayoría de los profesores la dio entonces nuestro grupo, y así nacieron, con éxito resonante, los cursos de humanidades y de ciencias". ${ }^{24}$ El maestro, siempre dispuesto a ayudar, ocupó la cátedra de literatura inglesa.

Los acontecimientos políticos desencadenados por la contra-revolución de Huerta en 1913 casi suspenden las actividades de los ateneístas. Esos "años terribles de 1913 a 1916 —nos dice don Pedro- hubieran dado fin a toda vida intelectual a no ser por la persistencia en el amor de la cultura que es inherente a la tradición latina". ${ }^{25}$ Lo que es peor, el grupo comenzaba a dispersarse. En agosto de 1913, Alfonso Reyes parte hacia España; Vasconcelos se encontraba al lado de los revolucionarios en el norte de la República. El maestro Caso y don Pedro seguían en la ciudad de México. Mas sus actividades son limitadas. Organizan, con don Francisco Gamoneda,

23 Henríquez Ureña, sin embargo, dice que la Universidad Popular se fundó en 1911: "Nuestro grupo, además, constituido en Ateneo en 1909, había funda. do en 1911 la Universidad Popular Mexicana, en cuyos estatutos figuraba la norma de no aceptar nunca ayuda de los gobiernos; esta institución duró diez años, atravesando ilesa las peores crisis del país, gracias al tesón infatigable de su rector, Alfonso Pruneda, y contó con públicos muy variados: entre los obreros difundió, en particular, conocimientos de higiene; y de sus conferencias para el público culto nacieron libros importantes, de Caso y de Mariscal, entre otros." ("La revolución y la cultura en México", p. 128).

24 Ibid Ver también supra, nota 6.

25 Ibid., p. 129. 
una serie de conferencias en la Librería General. El 6 de diciembre, Henríquez Ureña dicta su ya famosa conferencia sobre Ruiz de Alarcón, ${ }^{26}$ uno de los estudios que México más le agradece, ya que con él reintegró a la literatura mexicana la personalidad del autor de La verdad sospechosa. Su tesis sostiene que Ruiz de Alarcón pertenece de pleno a la literatura de México y representa de modo cabal el espíritu del pueblo mexicano. La conferencia fue acogida con entusiasmo, como es evidente por las reproducciones que de ella se hicieron en varias revistas, lo mismo que su traducción al francés. ${ }^{27}$ Años después, el autor la recogió, sin notas y con algunos retoques, en su libro Seis ensayos en busca de nuestra expresión. ${ }^{28}$

$\mathrm{Al}$ año de 1913 también pertenece su poco conocido estudio sobre las Traduccicnes y paráfrasis en la literatura mexicana de la época de la Independencia (1800-1821), publicado por el Museo Nacional. De dicho estudio, don Pedro, tal vez por consejo de Alfonso Reyes, envió un ejemplar al crítico francés $R$. Foulché-Delbosc desde la Secretaría de la Universidad de México. ${ }^{29}$ En su Revue Hispanique el benemérito hispanista le publicó, entre otros trabajos, su Bibliografía de Sor Juana Inés de la Cruz.s. Sobre la formación de esta erudita

26 Don Juan Ruiz de Alarón. Conferencia pronunciada en la Librería General de México el 6 de diciembre de 1913. Tirada aparte: La Habana, Impr. de "El Siglo XX", de Aureliano Miranda, 1915. Reproducida en Nosotros, México, núm. 9 (marzo de 1914), y en El libro y el pueblo, México, X, núm. 2.

27 Bibliotbèque Americaine, de la Universidad de París, 1924.

28 Buenos Aires, Biblioteca Argentina de Buenas Ediciones, 1928, pp. $79-99$

En 1922, Pedro Henríquez Ureña publicó en México, con Prólogo y Notas, la comedia Los favores del mundo, de Alarcón, y en 1938 la Introducción a una edición de La verdad sospechosa, que apareció en Buenos Aires. También habla de Alarcón en su estudio "Escritores españoles en la Universidad de México", Revista de filología española, XXII (1935), pp. 60-65.

29. Traducciones y paráfrasis en la literatura mexicana de la época de la Independencia (1800-1821), por Pedro Henríquez Ureña, en los Anales del Museo Nacional de Arqueologia, Historia y Etnografia, V (1913), 51-63. Tirada aparte: México, Imprenta del Museo Nacional de Arqueología, Historia y Etnografía, 1913, 13 pp. Ejemplar dedicado por el autor a Raymond Foulché-Delbosc en mi bibliteca. Sobre la misma época también publicó su estudio "La métrica de los poetas mexicanos de la Independencia", en el Boletín de la Biblioteca Nacional de México, VII (1914), 19-28.

30 Revue Hispanique, París, XL (1917), 161-214. Reproducida en El libro 
y meritoria bibliografía, don Pedro, allí mismo, nos dice: "A principios de 1914, di a la revista México —digna de mejor vida y circulación mayor de la que alcanzó- un breve artículo En pro de la edición definitiva de Sor Juana, al que acompañan sucintas notas bibliográficas (52 números) ... entre tanto, he añadido nuevos datos a mi bibliografía, en Washington y en Nueva York, y considero que en América no me sería fácil obtener muchos más" (pp. 161-162). Más tarde, sin embargo, la había de publicar en Buenos Aires (1937) corregida y añadida (ver nota 30 ). Su interés en Sor Juana, lo mismo que en Ruiz de Alarcón, perduró hasta los últimos días de su vida. ${ }^{31}$

Aunque algún crítico afirma que Henríquez Ureña salió de México en 1913, más bien parece que fue en 1914. De México pasa a Cuba, donde vivía su hermano Max, y de allí a los Estados Unidos. En ese año de 1914 lo encontramos en la Universidad de Minnesota, en Minneapolis. ${ }^{32}$ Los años que van de 1914 a 1920 allí los pasa, estudiando, dictando conferencias y escribiendo. Recibe el grado de Master of Arts, y poco después (junio de 1918) el de Doctor en Filosofía. En el verano de 1917, don Pedro había visitado a Alfonso Reyes en Madrid. De esa visita, don Alfonso recuerda interesante anécdota, que ilustra el carácter del dominicano: "Cierta vez —nos diceJosé Moreno Villa lo llevó al museo del Escorial. Pedro habló todo el tiempo de Minnesota —el clima, la Universidad, el catedrático de literatura francesa, una profesora que estudiaba la Divina Comedia, las reuniones dominicales en casa de algún colega- y no parecía prestar atención a lo que tenía adelante. Poco después, al regreso, en un misterioso desperezo retrospectivo, dejó pasmado a José Moreno Villa con un estupendo análisis del San Mauricio del Greco". ${ }^{33}$

El maestro dominicano, por supuesto, no permanece en

y el pueblo, México, XI (1934), 72-78; XII (1934), 137-43, 175-79, 229-35, 290-98, 336-44, 386-93, 436-41, con notas de E. Abreu Gómez; también en el Boletin del Instituto de Cultura Latino-Americana, Buenos Aires (1937), corregida $\mathrm{y}$ añadida.

31 Para otros trabajos de Pedro Henríquez Ureña sobre estos dos autores, véanse las referencias bibliográficas de la nota 4 .

32 Ver Abside, México, XIX (1955), p. 55.

33 Alfonso Reyes, Grata compañia (México, 1948), p. 210. 
España; su América le atrae. Vuelve a Minnesota, y de allí, llamado por José Vasconcelos — que acababa de ser nombrado Secretario de Educación (1920) - otra vez a México por una segunda temporada. Debido a su influencia sobre Vasconcelos, la Universidad Nacional editó los clásicos griegos. En 1921 salieron de las prensas universitarias las Tragedias de Eurípides, que Henríquez Ureña menciona en su bibliografía al artículo sobre Pérez de Oliva. Por esos años también, despertó en México - como resultado de la Revolución-el interés por el folklore y la literatura popular. Vasconcelos encargó a don Pedro que hiciera un estudio de los romances populares. Las primeras investigaciones serias sobre la divulgación del romance tradicional en México a él se deben. Dichos estudios "fueron hechos - dice don Vicente T. Mendoza- hará unos quince años, hacia 1922, cuando era Ministro de Educación el Lic. D. José Vasconcelos, y tenía como colaborador a D. Pedro Henríquez Ureña. En su obra Indología, el Lic. Vasconcelos dice que proyectaba publicar un Romancero; dicha obra no llegó a editarse -ignoro las causas-, ni sé tampoco si se intentaba que fuese solamente español o debía contener versiones mexicanas; me inclino a creer que fuese esto último, porque en el Homenaje a Menéndez Pidal, T. II, el señor Henríquez Ureña presenta diversas versiones recogidas entre personas conocidas de México y presumo que estaban destinadas a publicarse por la Secretaría de Educación. Como hasta ahora es éste el único trabajo de consideración que se ha llevado a término en este sentido, me ha sido valiosa su consulta e incluyo en mi obra dicha documentación". 34

Por aquellos años ya había surgido una nueva generación -Antonio Castro Leal, Alfonso Caso, Gómez Morín, Toussaint, Cosío Villegas, Lombardo Toledano, José Gorostiza- formada en las aulas de la Universidad Nacional, bajo el influjo decisivo de Antonio Caso y Pedro Henríquez Ureña. ${ }^{35}$ El órgano oficial del grupo era la revista México Moderno, que antes dirigiera el poeta González Martínez y entre cuyos directores encon-

34 El romance español y el corrido mexicano (México, 1939), pp. 61-62.

35 Sobre esta "Generación de 1915", ver José Luis Martínez, Literatura mexicana siglo XX, Primera parte (México, 1949), pp. 15-16. 
tramos el nombre de don Pedro. ${ }^{36}$ Allí publicó, en 1922, sus Notas sobre literatura mexicana. Sobre las aportaciones del grupo a la cultura mexicana, nos dice: "Hacia 1920 se hace franco cambio de orientación en la enseñanza de la sociología, la economía política y el derecho. Esta transformación se debe a hombres más jóvenes que nosotros, hombres que apenas alcanzan ahora [1925] los treinta años: Manuel Gómez Morín, a quien se debe en su mayor parte la nueva coordinación del plan de estudios jurídicos en la Universidad; Vicente Lombardo Toledano, cuyas Definiciones de derecho público, se inspiran en la escuela de Duguit; Daniel Cosío Villegas, cuyo intento de hacer sociología aplicada al país (apuntes de Sociología mexicana.) despierta franco interés; Alfonso Caso, Daniel Quiroz y otros. .." ${ }^{37}$

El magisterio de Henríquez Ureña en México termina en 1924, año en que decide pasar a la Argentina. Mas esto no indica que deje de pensar o escribir sobre México. Al año siguiente de su llegada a Buenos Aires da a la Revista de filosofí $a$ su estudio "La revolución y la cultura en México", 38 esquemática síntesis de la cultura mexicana, la primera del autor, que había de ampliar en obras posteriores, como la Historia de la cultura en la América Hispánica (México, 1947). Otros de sus estudios sobre temas y autores mexicanos los recogió en su libro - uno de los que más fama le han dado-Seis ensayos en busca de nuestra expresión (1928); tres de los seis estudios versan sobre la personalidad y las obras de autores mexicanos: Ruiz de Alarcón, Alfonso Reyes, González Martínez; ensayos, los tres, de capital importancia para el estudio de las letras mexicanas, y a los cuales hay que volver siempre.

En Buenos Aires, debido a la influencia del filólogo Amado Alonso, renace en don Pedro el interés por las investigaciones lingüústicas. Dos son las fuentes que utiliza para sus estudios del español en México, estudios indispensables sobre la materia: sus observaciones personales del habla popular y su

\footnotetext{
36 En el primer número (12 de agosto de 1922) colaboró con su ensayo "La antología de la ciudad". La editorial México Moderno le publicó su libro En la orilla: Mi España (1922).

37 "La revolución y la cultura en México", p. 129.

38 Ver nota 9.
} 
inmensa erudición. Las bibliografías que antepuso a la obra El español en Méjico, los Estados Unidos y la América Central (Buenos Aires, 1938), obra publicada con cuatro años de retraso a pesar de su empeño, son el mejor ejemplo de su prodigiosa erudición. La "Introducción", al mismo tiempo, es un enjundioso estudio sobre el español de esas regiones, y sus "Datos para el habla popular de Méjico" (pp. 277-324) aportan un insuperable modelo a los estudios de esta naturaleza $\mathrm{y}$, a la vez, demuestran el dominio que el autor poseía de la materia.

Hay, por fin, un aspecto de las actividades del maestro dominicano - el aspecto de su vida más difícil de captar-que es preciso mencionar: trátase de su obra no escrita. No hay duda de que, mientras vivió, hizo un gran esfuerzo por dar lo mejor a sus amigos, tanto en la conversación como en la enseñanza. En México creó ambiente intelectual. Entre sus discípulos encontramos a las mejores inteligencias del siglo. Los que mañana lean sus obras, dice Alfonso Reyes, apenas conocerán la mitad de su contenido humano y quién sabe si todavía menos. "Todo lo dejaba, todo, para acudir a los demás, y en ello gastó gran parte de su vida. Somos legión los responsables de que no haya dado cima a muchos más libros proyectados. Y no sólo hacía suyas nuestras empresas literarias: también nuestros enojos prácticos y nuestras vicisitudes morales. Un día, cuando más pobre estaba, hizo entrega de sus parvos ahorros en manos de uno a quien quería ver inconmovible en su apartada dignidad cívica" (Grata compañía, p. 208).

En conclusión, podríamos decir que las principales aportaciones de don Pedro a la cultura mexicana son: en el campo de las letras, la revalorización de Ruiz de Alarcón, los estudios sorjuanísticos, los importantísimos estudios de revalorización del siglo XVIII, la Antología del Cenenario, la valorización de las obras de Alfonso Reyes y González Martínez, y sus trabajos filológicos; en el campo de las ideas: la ayuda que dio a la lucha contra el positivismo, la orientación de los jóvenes que formaron el Ateneo de la Juventud y, más tarde, al grupo llamado generación de 1915; en la educación: su colaboración en la organización de la Universidad Popular y la reorganización de la Escuela de Altos Estudios, hoy Universidad Nacional; y, en fin, en el campo de las relaciones humanas: su ayuda 
a todos los jóvenes que se le acercaban a pedirla, ya fuera intelectual, moral o material. Con razón Alfonso Reyes, quien mejor lo conoció, ha dicho: "México reclama el derecho de llorarlo por suyo. Pocos, sean propios o extraños, han hecho tanto en bien de México. Aquí transcurrió su juventud ... aquí en señó entre sus iguales, sus menores y sus mayores; y en corto plazo, hizo toda la carrera y ganó el título de abogado. Aquí gobernaba con intimidad y sin rumor aquellas diminutas $y$ sucesivas pléyades, cuyas imágenes van convirtiéndose ya en focos orientadores a los ojos de la mocedad más promisora. Aquí se incorporó en las trascendentales reformas de la educación pública. Aquí fundó su hogar. Y, al cabo, nos ayudó a entender $y$, por mucho, a descubrir a México. Nuestro país era siempre el plano de fondo en su paisaje vital, la alusión secreta y constante de todas sus meditaciones" (Grata compañía, p. 206).

iSirvan estas desaliñadas notas de humilde homenaje al inolvidable maestro!

LUIS LEAL,

Emory University, Georgia, EE. UU. 
